\title{
Escovopsioides as a fungal antagonist of the fungus cultivated by leafcutter ants
}

\author{
Julio Flavio Osti ${ }^{1}$ and Andre Rodrigues ${ }^{1,2^{*}}$ (D)
}

\begin{abstract}
Background: Fungus gardens of fungus-growing (attine) ants harbor complex microbiomes in addition to the mutualistic fungus they cultivate for food. Fungi in the genus Escovopsioides were recently described as members of this microbiome but their role in the ant-fungus symbiosis is poorly known. In this study, we assessed the phylogenetic diversity of 21 Escovopsioides isolates obtained from fungus gardens of leafcutter ants (genera Atta and Acromyrmex) and non-leafcutter ants (genera Trachymyrmex and Apterostigma) sampled from several regions in Brazil.

Results: Regardless of the sample locality or ant genera, phylogenetic analysis showed low genetic diversity among the 20 Escovopsisoides isolates examined, which prompted the identification as Escovopsioides nivea (the only described species in the genus). In contrast, one Escovopsioides isolate obtained from a fungus garden of Apterostigma megacephala was considered a new phylogenetic species. Dual-culture plate assays showed that Escovopsioides isolates inhibited the mycelium growth of Leucoagaricus gongylophorus, the mutualistic fungus cultivated by somes species of leafcutter ants. In addition, Escovopsioides growth experiments in fungus gardens with and without ant workers showed this fungus is detrimental to the ant-fungus symbiosis.
\end{abstract}

Conclusions: Here, we provide clues for the antagonism of Escovopsioides towards the mutualistic fungus of leafcutter ants.

Keywords: Hypocreales, Attine ants, Escovopsis, Symbiosis

\section{Background}

Fungus-growing ants in the tribe Attini are found only on the American continent [1]. These insects cultivate fungi as the main food source for the colony [2]. As a subgroup within the higher attines, leafcutter ants in the genera Atta and Acromyrmex use fresh leaves and flowers as substrate to nourish the fungus cultivar. Leafcutter ants cultivate two phylogenetic clades of fungi including Leucoagaricus gongylophorus (Basidiomycota: Agaricales) [3]. In turn, the fungal partner is cultivated on fragments of plant substrate processed by the ants in a structure named "fungus garden" [2]. Due to the high amount of leaves that leafcutter ants collect, these insects are considered agricultural pests, causing serious damage to several crops [4].

Contrary to what was proposed by Weber [2], L. gongylophorus is not the only active microorganism in the fungus

\footnotetext{
* Correspondence: andrer@rc.unesp.br

'Department of Biochemistry and Microbiology, São Paulo State University (UNESP), Rio Claro, Brazil

${ }^{2}$ Center for the Studies of Social Insects, São Paulo State University (UNESP), Rio Claro, Brazil
} Rio Claro, Brazil garden. In fact, a diverse and rich microbial community consisting of bacteria, yeasts, and filamentous fungi are also found in this substrate [5-7]. Some of these microorganisms can compete for nutrients with the mutualistic fungus [8], others act as parasites of the fungal cultivar [9]. In addition, there are beneficial microbes in the fungus gardens, which may help the mutualistic fungus against pathogens [10]. Actinobacteria present on the workers' cuticles also assist in the protection of the colony against invading microorganisms [11-13].

Currie and colleagues [14] showed that fungi in the genus Escovopsis (Ascomycota: Hypocreales) cause negative impacts on attine ant colonies. Multiple lines of evidence suggest that Escovopsis is a specialized parasite of the ant cultivar, using both chemical and physical mechanisms to attack its host $[9,15,16]$. Escovopsis shares an ancient evolutionary history with the mutualistic fungus and the ants, indicating that the origin of this parasite occurred concomitantly with the beginning of the ant-fungus association, about 50-65 million years ago [17]. 
Recently, fungi in the genus Escovopsioides (Ascomycota: Hypocreales) were described from fungus gardens of the leafcutter ants Acromyrmex niger, Acromyrmex subterraneus molestans and Acromyrmex subterraneus subterraneus [18]. Also, this fungus was found in $24 \%$ to $72 \%$ of the sampled colonies in different localities in Brazil [18-20]. Escovopsioides shares some morphological characteristics with Escovopsis but differ in others such as terminal vesicles with long (lageniform) phialides and hyphae with aleuroconidia. Molecular analysis indicates that Escovopsioides is phylogenetically related to Escovopsis [18]. The discovery of this fungus launched new research windows on the attine ant-fungus symbiosis. First, nothing is known about the diversity and taxonomy of Escovopsioides. So far, only one species ( $E$. nivea) has been described from a very narrow geographical range ("Mata do Paraíso", Viçosa, state of Minas Gerais, Brazil); however, it is likely that other species in the genus still await discovery. Second, if Escovopsioides is an antagonist of the mutualistic fungus as suggested by Varanda-Haifig et al. [16], new opportunities will rise to study the dynamics of the evolution of additional detrimental fungi to the fungus gardens of attine ants. Third, it is not clear whether Escovopsioides can cause detrimental effects to fungus gardens of attine ants, or whether the ant workers protect the fungus gardens against Escovopsioides.

We obtained several Escovopsioides isolates from fungus gardens of different associated attine ant genera (Atta,
Acromyrmex, Trachymyrmex and Apterostigma) and posed the following questions: (i) given that Escovopsioides was described from fungus gardens of Acromyrmex spp., do isolates of this fungus found on colonies of other genera of attine ants form a monophyletic clade?, (ii) are Escovopsioides from different associated attine ant species antagonists of the $L$. gongylophorus and the fungus gardens?, and (iii) is Escovopsioides capable to overcome the protective roles of the ant workers? We show that Escovopsioides associated with a wide range of ant species from various geographical areas belong to the same species (E. nivea). Our results also support previous findings [16] of the antagonism of this fungus towards the mutualistic cultivar of leafcutter ants.

\section{Results}

\section{Escovopsioides phylogeny}

Our analysis resolved a single, well-supported monophyletic clade of Escovopsiodes, with one isolate falling just outside of this clade, namely isolate Escovopsioides sp. LESF 602 (Fig. 1). We observed low genetic diversity in the main clade, comprising isolates associated with the higher-attine ant genera Atta, Acromyrmex and Trachymyrmex along with the type species, E. nivea CBS $135749^{\mathrm{T}}$. A low intraspecific variation (99.1 to $100 \%$ similarity) among Escovopsioides isolates of higher-attines was observed in the tef1 marker. Interesting to note, the genetic similarity in the tef1 gene was observed for isolates from distant geographic regions, since Escovopsioides isolates obtained from colonies separated by large

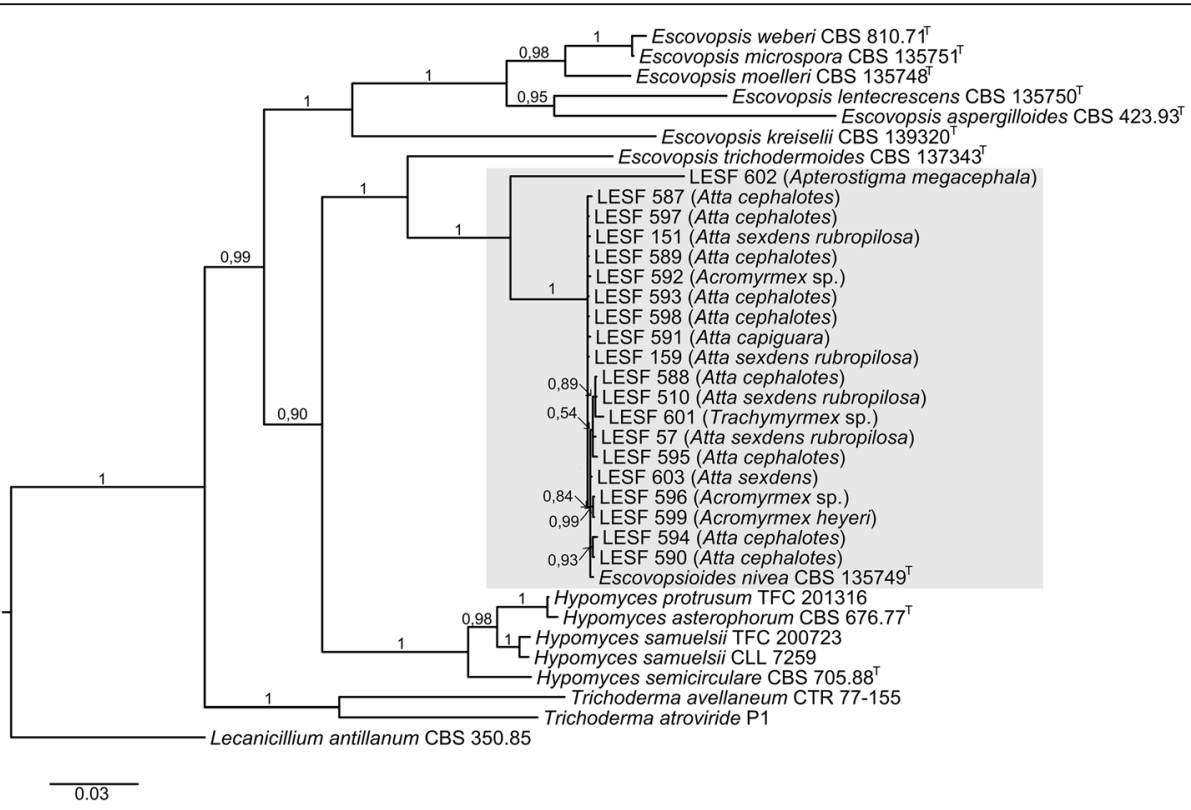

Fig. 1 Phylogeny of Escovopsioides isolates obtained from fungus-growing ants. The tree was reconstructed under Bayesian Inference (BI) using concatenated sequences of tef1 and LSU genes as well as ITS. Sequences of type strains of Escovopsis spp. (represented by ${ }^{\top}$ ) and additional hypocrealean fungi (outgroup) were retrieved from GenBank (Additional file 1: Table S1). Values on branches are posterior probabilities. The entire alignment is composed of 2112 bp in length. The substituion models GTR + G for tef1 and GTR + I + G for ITS and LSU were used in the BI analysis. Escovopsioides species are indicated by LESF Ids and associated ant species are indicated in parentheses. All other sequences are followed by the culture collection accessions 
distances were similar, such as Rio Grande do Sul and Bahia states (Fig. 1). The low intraspecific variation was also observed in the ITS region (99.4 to $100 \%$ of similarity). The LSU sequences were identical among 20 out of 21 sequences. On the other hand, Escovopsioides sp. LESF 602 obtained from fungus gardens of Apterostigma megacephala presented similarity between 90 to $91 \%$ in relation to the other isolates considering the marker tef1; $91 \%$ to $92 \%$ for ITS and $98 \%$ of similarity for LSU. This isolate stands out in the phylogeny as a separate branch and indicates a not yet described phylogenetic species (Fig. 1).

\section{Dual-culture bioassays}

A total of 12 out of 14 evaluated fungi (13 Escovopsioides and 1 Escovopsis) significantly inhibited the mycelial growth of L. gongylophorus FF2006 after 10 days (two-way mixed ANOVA, $P<0.009$, Table 1). Except for $E$. nivea LESF 596 and Escovopsioides sp. LESF 602, the remaining Escovopsioides isolates inhibited the growth of this fungus between the 3rd and 7th days of experiment (Bonferroni test, $P<0.01$ ). Inhibition of the mutualistic fungus by isolates LESF 596 and LESF 602 was only observed between the 7th and 10th day (Bonferroni test, $P<0.01$, Table 1). On the other hand, significant inhibition of mycelial growth of L. gongylophorus by Escovopsis was observed on the 2nd day of the experiment (Bonferroni test, $P<0.01$, Table 1). All Escovopsioides isolates began to significantly inhibit L. gongylophorus when contact between colonies of the two fungi occurred, when the mutualistic fungus generally acquired a brown coloration.

After 10 days of experiment three significantly distinct groups of Escovopsioides isolates were observed regarding the inhibition of the mutualistic fungus (Fig. 2). Isolates LESF 596 and LESF 602, obtained from Acromyrmex sp. and A. megacephala, respectively, comprise a group of fungi that significantly inhibited the growth of the mutualistic fungus at day 10, but to a lesser extent when compared to the remaining isolates (Tukey-HSD, $P<0.003$, Fig. 2). Escovopsis showed the highest inhibiton of the mutualistic fungus (Tukey-HSD, $P<0.001$, Fig. 2).

\section{Bioassays on fungus garden fragments in the absence of workers}

Overall, Escovopsioides isolates and Escovopsis grew on fungus gardens and no differences were observed in their development (Fig. 3a and Additional file 1: Figure S1). Escovopsioides sp. LESF 602 was the only isolate that did not grow on the fungus gardens after 10 days (Fig. 3a). On day 10 of the experiment, 11 out of 12 Escovopsioides isolates presented conidiation on the fungus gardens. The exception was E. nivea LESF 594, which did not produce conidia on the fungus gardens.

\section{Effects of Escovopsioides on gardens with workers}

We observed three main responses when inoculating garden fragments with the presence of workers. The first one was observed for the majority of Escovopsioides isolates along with the Escovopsis isolate. For this group, we recorded significant damage in the fungus gardens $(P<0.049$, Fig. 3b). Fungus gardens treated with conidia of these fungi succumbed and most of the infected fungus gardens were removed and degraded (Additional file 1: Figure S2). We observed Escovopsioides growth in fragments of this substrate when inoculated on the culture medium (Table 2).

Table 1 Mycelial growth (mean areas \pm standard errors, in $\mathrm{cm}^{2}$ ) and interval of inhibition of Leucoagaricus gongylophorus, the fungus cultivated by the leafcutter ant Atta sexdens rubropilosa. T: type species of Escovopsioides nivea

\begin{tabular}{|c|c|c|c|c|c|c|}
\hline Isolate ID & Fungi & $C G_{d 10}$ & $\mathrm{FG}_{\mathrm{d} 10}$ & Int-In & F value & $P$ value \\
\hline LESF 19 & Escovopsis sp. & $8.97 \pm 0.07$ & $3.43 \pm 0.07$ & $0-2$ & 320.43 & $<0.001$ \\
\hline LESF 601 & Escovopsioides nivea & $8.97 \pm 0.07$ & $4.36 \pm 0.12$ & $3-5$ & 127.26 & $<0.001$ \\
\hline LESF 590 & Escovopsioides nivea & $9.10 \pm 0.13$ & $5.20 \pm 0.10$ & $3-5$ & 103.81 & $<0.001$ \\
\hline CBS $135749^{\top}$ & Escovopsioides nivea & $8.09 \pm 0.13$ & $4.37 \pm 0.09$ & $3-5$ & 59.02 & $<0.001$ \\
\hline LESF 594 & Escovopsioides nivea & $9.10 \pm 0.13$ & $5.46 \pm 0.12$ & $3-5$ & 48.56 & $<0.001$ \\
\hline LESF 595 & Escovopsioides nivea & $8.51 \pm 0.16$ & $4.51 \pm 0.12$ & $3-5$ & 44.10 & $<0.001$ \\
\hline LESF 510 & Escovopsioides nivea & $8.20 \pm 0.12$ & $4.18 \pm 0.07$ & $3-5$ & 44.03 & $<0.001$ \\
\hline LESF 591 & Escovopsioides nivea & $8.95 \pm 0.16$ & $5.87 \pm 0.18$ & $5-7$ & 26.71 & $<0.001$ \\
\hline LESF 151 & Escovopsioides nivea & $8.19 \pm 0.13$ & $4.24 \pm 0.11$ & $5-7$ & 16.26 & $<0.001$ \\
\hline LESF 603 & Escovopsioides nivea & $8.36 \pm 0.20$ & $4.45 \pm 0.16$ & $5-7$ & 14.45 & 0.001 \\
\hline LESF 592 & Escovopsioides nivea & $8.36 \pm 0.18$ & $5.42 \pm 0.17$ & $5-7$ & 14.26 & 0.001 \\
\hline LESF 599 & Escovopsioides nivea & $8.36 \pm 0.18$ & $6.00 \pm 0.12$ & $5-7$ & 13.85 & 0.001 \\
\hline LESF 596 & Escovopsioides nivea & $8.36 \pm 0.20$ & $6.85 \pm 0.19$ & $7-10$ & 0.84 & 0.370 \\
\hline LESF 602 & Escovopsioides sp. & $8.20 \pm 0.12$ & $6.65 \pm 0.15$ & $7-10$ & 0.35 & 0.558 \\
\hline
\end{tabular}

$\mathrm{CGd}_{10}$ : growth area of L. gongylophorus in the control plates at day 10; $\mathrm{FG}_{\mathrm{d} 10}$ : growth area of L. gongylophorus in the presence of Escovopsioides or Escovopsis at day 10 , Int-In: inhibition interval (in days). Significant differences between $C \mathrm{Gd}_{10}$ and $\mathrm{FG}_{\mathrm{d} 10}$ were verified by pairwise $\mathrm{t}$-test with Bonferroni correction $(P<0.01)$ 


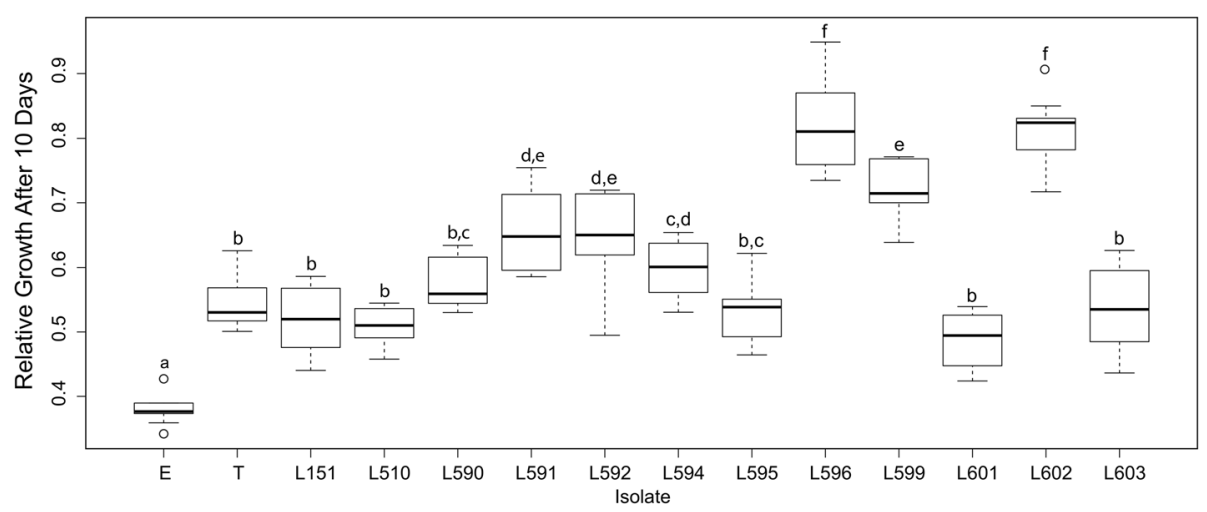

Fig. 2 Mycelial growth of Leucoagaricus gongylophorus, the fungus cultivated by leaf-cutter ants, in the presence of Escovopsisoides isolates. The relative mycelial growth was obtained by dividing the growth area of $L$. gongylophorus towards the different Escovopsioides isolates in relation to the corresponding control (absence of Escovopsioides) after 10 days. Data followed by different letters are significantly different (P $\leq 0.05)$. E: Escovopsis sp. LESF 19 was used for comparison. T: type species of Escovopsioides nivea. L: refers to the LESF Ids of Escovopsioides strains listed in Table 3
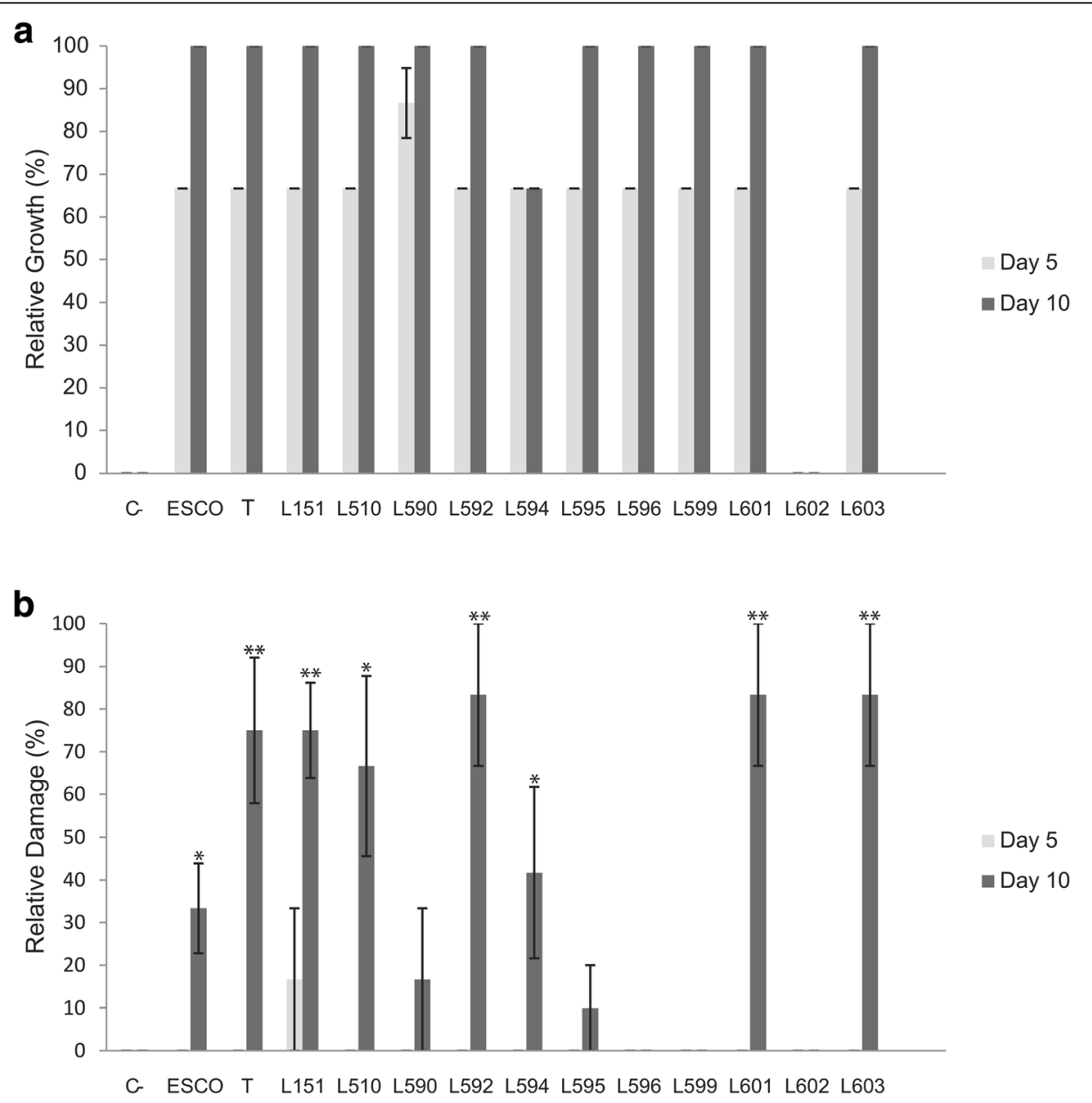

Fig. 3 Fungus gardens of Atta sexdens rubropilosa treated with Escovopsoides conidia. (a) Ant-free fungus gardens and (b) Fungus gardens with ant workers. Light gray bars: treatments after 5 days. Dark grey bars: treatments after 10 days. The $y$-axis indicates relative growth of Escovopsioides (a) and damage (in \%) on fungus gardens (b). Values are means \pm standard errors of proportions of the scores in the different treatments. * and ** indicates significant damage on fungus gardens with workers $P \leq 0.05$ and $P \leq 0.01$, respectively. ESCO: Escovopsis sp. LESF 19 was used for comparison. T: type species of Escovopsioides nivea; C-: negative control. L followed by numbers refers to the LESF Ids listed in Table 3 
Table 2 Presence of Escovopsioides in fungus gardens of Atta sexdens rubropilosa after 0, 5 and 10 days of treatment with conidia of this fungus. The values are means \pm standard errors of garden fragments with conidia on a scale of percentage, with 0 (no conidia present on garden fragments) to 100 (conidia present on all garden fragments). Data followed by different letters are significantly different between treatments in the same day $(P \leq 0.05)$. Escovopsis sp. LESF 19 was used for comparison. 'T: type species of Escovopsioides nivea

\begin{tabular}{llll}
\hline Isolates & Day 0 & Day 5 & Day 10 \\
\hline Control & $0 \mathrm{a}$ & $0 \mathrm{a}$ & $0 \mathrm{a}$ \\
LESF 596 & $100 \mathrm{~b}$ & $48.27 \pm 14.79 \mathrm{~b}, \mathrm{c}$ & $44.82 \pm 13.53 \mathrm{c}, \mathrm{d}$ \\
LESF 599 & $100 \mathrm{~b}$ & $73.91 \pm 22.75 \mathrm{c}, \mathrm{d}$ & $26.08 \pm 9.52 \mathrm{~b}, \mathrm{c}$ \\
LESF 602 & $100 \mathrm{~b}$ & $33.33 \pm 8.78 \mathrm{~b}$ & $4.76 \pm 4.76 \mathrm{a}, \mathrm{b}$ \\
LESF 590 & $100 \mathrm{~b}$ & $103.57 \pm 3.57 \mathrm{f}$ & $71.42 \pm 14.28 \mathrm{~d}$ \\
LESF 595 & $100 \mathrm{~b}$ & $84 \pm 7.48 \mathrm{~d}, \mathrm{e}$ & $60 \pm 17.12 \mathrm{~d}$ \\
LESF 151 & $100 \mathrm{~b}$ & $100 \mathrm{f}$ & $70 \pm 16.93^{*}$ \\
LESF 510 & $100 \mathrm{~b}$ & $100 \mathrm{f}$ & $16.66 \pm 16.66^{*}$ \\
LESF 592 & $100 \mathrm{~b}$ & $93.33 \pm 6.66 \mathrm{~d}, \mathrm{e}, \mathrm{f}$ & $33.33 \pm 15.20^{*}$ \\
LESF 594 & $100 \mathrm{~b}$ & $82.14 \pm 8.60 \mathrm{~d}, \mathrm{e}$ & $46.42 \pm 20.26^{*}$ \\
LESF 601 & $100 \mathrm{~b}$ & $96.66 \pm 3.33 \mathrm{e}, \mathrm{f}$ & $10 \pm 10^{*}$ \\
LESF 603 & $100 \mathrm{~b}$ & $100 f$ & $70 \pm 10^{*}$ \\
CBS 135749 & $100 \mathrm{~b}$ & $100 f$ & $20 \pm 10.32^{*}$ \\
ESCOvopsis sp. LESF 19 & $100 \mathrm{~b}$ & $100 \mathrm{f}$ & $100^{*}$ \\
\hline
\end{tabular}

"Values not considered in the analysis, since they refer to Escovopsioides growth in waste material, not from the fungus garden

However, fast-growing fungi also grew along with Escovopsioides and covered the Petri dishes. Because of that we could not recover Escovopsioides from all containers in these treatments. Thus, all data obtained from the infected fungus garden were not used in the comparative analyses with fungi isolated from the healthy fungus gardens.

The second response consisted of observations for $E$. nivea LESF 590 and LESF 595. A moderate reduction in the frequency of recovery of these fungi was observed (Table 2). In addition, the health conditions of the fungus gardens infected with the two isolates did not differ significantly from that of the control, although a slight decrease in garden health was observed $(P>0.36$, Fig. $3 b)$.

Finally, the third response was observed for the isolates LESF 596 and LESF 599, where great removal of conidia was observed on day 10 (Table 2). In addition, conidia of Escovopsioides sp. LESF 602 was almost completely absent from the fungus gardens on day 10 . Thus, fungus gardens inoculated with conidia of these three isolates were completely healthy on day $10(P=1.00$, Fig. $3 \mathrm{~b})$.

\section{Discussion}

Here, we showed for the first time that E. nivea is found in colonies of different higher attine ants from distinct geographic regions. In addition, in vitro bioassays coupled with experiments using both fungus gardens with and without tending ants showed this fungus is an effective antagonist of the mutualistic fungus cultivated by leafcutter ants.

The Bayesian inference resolved Escovopsoides in a monophyletic clade and as a sister group of Escovopsis supporting results found by Augustin et al. [18]. Most of the isolates ( $n$ $=20$ ) showed low variation in the molecular markers, corroborating the identification to the type species, $E$. nivea described by Augustin et al. [18]. The only exception was Escovopsioides sp. LESF 602, obtained from a colony of $A$. megacephala, which diverged from the type species of the genus, suggesting a new phylogenetic species. The description of this new taxon will be provided in future studies as the quest for additional isolates of this taxon continues. Moreover, the genus Escovopsioides needs to be further investigated to unravel its diversity, especially in lower attine ants, from which there are no reports of its occurrence.

In the analysis we noted that the sample locality does not explain the clustering of the several Escovopsioides isolates. A similar result was observed by Taerum et al. [21] for Escovopsis isolates obtained from very distant places, such as Panama and Argentina. Moreover, these authors also did not observe a separation of Escovopsis that infects Atta colonies and others that only infect Acromyrmex colonies, demonstrating a high degree of parasite sharing among leafcutter ants. Similarly, we observed that Atta, Acromyrmex and Trachymyrmex share the same species (E. nivea) in their colonies.

Our data suggests that Escovopsioides is an antagonist of the ant mutualistic fungus. Varanda-Haifig et al. [16] raised indications that Escovopsioides shows inhibitory activity against the mutualistic fungus of leafcutter ants, but the authors used only two isolates obtained from ants in the genus Acromyrmex. The inhibitory activity of Escovopsioides could be verified from putative compounds produced by this fungus during hyphae-hyphae interaction [16]. Here, our experiments further support these results by assessing a more comprehensive set of isolates from diverse attine ant colonies. In addition, we also observed that Escovopsioides is an antagonist of the L. gongylophorus in its natural substrate (i.e. fungus gardens) in the absence or presence of worker ants.

In a context considering the protective role of the ants, the effect of some isolates changed significantly in comparison to the experiment in the absence of workers, because they did not cause significant damage in the fungus gardens with workers. Elizondo-Wallace and colleagues [22] observed that Escovopsis bearing identical tef1 gene sequences showed marked differences in garden damage in the presence of Atta cephalotes workers. Moreover, Taerum et al. [21] discussed the possibility that subtle genetic differences among Escovopsis isolates may have a very significant impact on the virulence of the parasite in the presence of workers. This may explain why the effect of 
genetically similar Escovopsioides isolates showed marked differences in the health of fungus gardens with workers. Therefore, this observation is evidence of how essential workers are in maintaining the health of fungus gardens.

We observed an absence of significant damage in fungus gardens infected with conidia of $E$. nivea LESF 596 and LESF 599. In addition, we observed that the frequency of detection of these isolates in fungus gardens with workers after treatment was significantly reduced overtime, suggesting the infection was under control (Fig. 3). This result could be due to the protective behavior of the ants by weeding out contaminated portions of the fungus garden or removing conidia by grooming [21]. On the other hand, in treatments with isolates LESF 151, LESF 510, LESF 592, LESF 594, LESF 601, LESF 603, CBS $135749^{\mathrm{T}}$ and Escovopsis sp. LESF 019, where severe damage was observed in the fungus garden, the partial or complete weeding of the infected fungus garden was observed (Additional file 1: Figure S2). Ants' dumps are recognized as a decomposing material rich in microorganisms, where a distinct microbiota from that found in the fungus garden prevails [23]. Several exogenous microorganisms to the ant colony may potentially outcompete and inhibit the development of Escovopsioides on the culture medium [24]. This may explain why Escovopsioides growth was often not observed when inoculating infected garden fragments on culture medium (Table 2).

Escovopsioides nivea LESF 601 was isolated from a colony of the higher attine ant genus Trachymyrmex. This genus like Atta and Acromyrmex belongs to the higher-attines, but cultivates a different fungus from that of the leafcutter ants (data not shown). The effect of LESF 601 in the dual-culture experiments against L. gongyloporus as well as on the fungus garden in the absence and presence of workers was indistinguishable from the most virulent isolates obtained from leafcutter ants (Fig. 3). Taerum et al. [21] observed the growth of Escovopsis isolates associated with Trachymyrmex ants on fungus gardens of leafcutter ants. Therefore, our results may suggest that Escovopsioides appears not to present specificity to its host, when considering leafcutter ants and non-leafcutter ants. However, this hypothesis should be tested further since in our experiments we challenged Escovopsioides only with one host fungus (L. gongylophorus). Thus, specificity and the variations observed regarding the antagonism of different Escovopsioides isolates may differ when using other fungal hosts such as those from non-leafcutter ants.

Escovopsioides sp. LESF 602 is the only isolate obtained from a lower attine ant colony, A. megacephala. This ant is distinguished from other species of Apterostigma by cultivating L. gongylophorus, the same mutualistic fungus cultivated by leafcutter ants [25]. Because this ant species cultivates this fungus, it was expected that the Escovopsioides found in this colony would cluster with all other Escovopsioides isolates found in leafcutter ant colonies. Contrary to the expected, LESF 602 was the most distinguished isolate in our phylogeny. Additionally, this isolate was the only one that did not demonstrate any effects in the fungus gardens both in the absence and in the presence of workers. Caldera and Gerardo [26] and Meirelles et al. [27] suggested that Escovopsis isolates are more adapted to particular geographic regions (local specialization). In the case of $A$. megacephala, this is a rare species found only in the Amazon region [25] and although these authors described the mutualistic fungus L. gongylophorus as the $A$. megacephala cultivar, this fungus belongs to a unique clade. Therefore, Gerardo et al. [28] appointed that different Escovopsis isolates attack only specific hosts through chemotaxis with the host also being able to protect itself with antibiotics against no specific Escovopsis. This may indicate certain specificity in Escovopsioides for the mutualistic fungus of this ant. In this sense, this could explain why LESF 602 is different than the other isolates, and the absence of damages in the mutualistic fungus used in the bioassays. However, this suspisions can be only confirmed when more isolates of this species become available.

\section{Conclusions}

Here, we showed low genetic diversity among Escovopsioides isolates from higher attine ants, showing a wide distribution of $E$. nivea in different ant colonies in distinct localities. More sampling efforts for Escovopsioides isolates may expand the diversity of this genus especially those associated with lower attine ants. The present study also indicated that Escovopsioides is an antagonist of the fungus gardens of leafcutter ants.

\section{Methods}

Fungi examined

Escovopsioides isolates were obtained from fungus gardens of different leafcutter and non-leafcutter ant species collected in previous studies [18-20, 29, 30]. This collection comprises 20 isolates obtained from Atta sexdens, Atta capiguara, Atta cephalotes, Acromyrmex balzani, Acromyrmex heyeri, Acromyrmex lundi and Trachymyrmex tucumanus, in addition to the type species of $E$. nivea obtained from Acromyrmex subterraneus subterraneus (Table 3). Also, one additional isolate was obtained from a colony of the non-leafcutter ant Apterostigma megacephala found in Parauapebas, Pará, Brazil (Table 3). All isolates displayed the described morphological characteristics of the genus Escovopsioides: hyaline colonies on PDA, terminal and intercalary vesicles bearing lageniform phialides, hyaline conidia in long chains, aleuroconidia and chlamydospore-like structures [18].

The isolates are kept as conidia suspensions at $-80^{\circ} \mathrm{C}$ (in glycerol $10 \%$ ) and in distilled water at $10{ }^{\circ} \mathrm{C}$ in the collection of the Laboratory of Fungal Ecology and Systematics (LESF), Rio Claro, São Paulo State, Brazil. All isolates were revived 
Table 3 Escovopsioides isolates $(n=21)$ obtained from fungus gardens of attine ants and used in the present study

\begin{tabular}{|c|c|c|c|c|c|}
\hline Isolate ID ${ }^{a}$ & Ant species & City/State & Coordinates of ant colonies & Colony Id ${ }^{b}$ & Reference \\
\hline LESF 57 & Atta sexdens rubropilosa & Corumbataí/SP & $22^{\circ} 17^{\prime} 22^{\prime \prime S} 47^{\circ} 39^{\prime} 23^{\prime \prime} \mathrm{W}$ & Colony 4 & [29] \\
\hline LESF $151^{c}$ & Atta sexdens rubropilosa & Corumbataí/SP & $22^{\circ} 17^{\prime} 22^{\prime \prime S} 47^{\circ} 39^{\prime} 23^{\prime \prime} \mathrm{W}$ & Colony 9 & [29] \\
\hline LESF 159 & Atta sexdens rubropilosa & Corumbataí/SP & $22^{\circ} 17^{\prime} 22^{\prime \prime S} 47^{\circ} 39^{\prime} 23^{\prime \prime} \mathrm{W}$ & Colony 7 & [29] \\
\hline LESF $510^{c}$ & Atta sexdens rubropilosa & Botucatu/SP & $22^{\circ} 54^{\prime} 28.44^{\prime \prime S} 48^{\circ} 18^{\prime} 55.68^{\prime \prime} \mathrm{W}$ & JSP130130-04 & [20] \\
\hline LESF 587 & Atta cephalotes & Camacan/BA & $15^{\circ} 23^{\prime} 18.18^{\prime \prime S} 39^{\circ} 33^{\prime} 30.54^{\prime \prime} \mathrm{W}$ & BMSR120704-01 & [19] \\
\hline LESF 588 & Atta cephalotes & Camacan/BA & $15^{\circ} 25^{\prime} 32.28^{\prime \prime S} 39^{\circ} 32^{\prime} 48.06^{\prime \prime} \mathrm{W}$ & BMSR120804-01 & [19] \\
\hline LESF 589 & Atta cephalotes & Camacan/BA & $15^{\circ} 23^{\prime \prime} 14.82^{\prime \prime S} 39^{\circ} 33^{\prime} 28.38^{\prime \prime} \mathrm{W}$ & BMSR120702-01 & [19] \\
\hline LESF $590^{\circ}$ & Atta cephalotes & Camacan/BA & $15^{\circ} 23^{\prime \prime} 15.18^{\prime \prime S} 39^{\circ} 33^{\prime} 28.02^{\prime \prime W}$ & BMSR130220-01 & [19] \\
\hline LESF $591^{c}$ & Atta capiguara & Botucatu/SP & $22^{\circ} 54^{\prime} 26.64^{\prime \prime S} 48^{\circ} 18^{\prime} 29.22^{\prime \prime} \mathrm{W}$ & JSP130307-03 & [20] \\
\hline LESF $592^{c}$ & Acromyrmex balzani & Camacan/BA & $15^{\circ} 22^{\prime} 50.34^{\prime \prime S} 39^{\circ} 34^{\prime} 3.54^{\prime \prime} \mathrm{W}$ & ARFVG1 10517-01 & - \\
\hline LESF 593 & Atta cephalotes & Camacan/BA & $15^{\circ} 23^{\prime \prime} 17.76^{\prime \prime S} 39^{\circ} 33^{\prime} 22.26 " \mathrm{~W}$ & BMSR120703-01 & [19] \\
\hline LESF $594^{c}$ & Atta cephalotes & Camacan/BA & $15^{\circ} 25^{\prime} 32.28^{\prime \prime S} 39^{\circ} 32^{\prime} 48.06^{\prime \prime} \mathrm{W}$ & BMSR120804-01 & [19] \\
\hline LESF $595^{\circ}$ & Atta cephalotes & Camacan/BA & $15^{\circ} 23^{\prime \prime} 14.82^{\prime \prime S} 39^{\circ} 33^{\prime} 28.38^{\prime \prime} \mathrm{W}$ & BMSR120702-01 & [19] \\
\hline LESF $596^{c}$ & Acromyrmex lundi & Chuvisca/RS & $30^{\circ} 50^{\prime} 10.2^{\prime \prime S} 51^{\circ} 55^{\prime} 10.4^{\prime \prime} \mathrm{W}$ & AOMB110904-02 & [30] \\
\hline LESF 597 & Atta cephalotes & Camacan/BA & $15^{\circ} 23^{\prime} 29.7^{\prime \prime S} 39^{\circ} 33^{\prime} 31.32^{\prime \prime} \mathrm{W}$ & BMSR120703-02 & [19] \\
\hline LESF 598 & Atta cephalotes & Camacan/BA & $15^{\circ} 23^{\prime \prime} 17.76^{\prime \prime S} 39^{\circ} 33^{\prime} 22.26^{\prime \prime} \mathrm{W}$ & BMSR120703-01 & [19] \\
\hline LESF $599^{c}$ & Acromyrmex heyeri & Sentinela do Sul/RS & $30^{\circ} 37.57^{\prime} 9.0^{\prime \prime} \mathrm{S} 51^{\circ} 33^{\prime} 18.2^{\prime \prime} \mathrm{W}$ & AOMB100904-03 & [30] \\
\hline LESF $601^{c}$ & Trachymyrmex tucumanus & Rio Claro/SP & $22^{\circ} 23^{\prime} 45.84^{\prime \prime S} 47^{\circ} 32^{\prime} 41.58^{\prime \prime} \mathrm{W}$ & SES080402-04 & - \\
\hline LESF $602^{c}$ & Apterostigma megacephala & Parauapebas/PA & $6^{\circ} 3^{\prime} 46.98^{\prime \prime S} 50^{\circ} 3^{\prime} 27.54 " \mathrm{~W}$ & JSC110910-03 & - \\
\hline LESF $603^{c}$ & Atta sexdens rubropilosa & Corumbataí/SP & $22^{\circ} 17^{\prime} 22^{\prime \prime S} 47^{\circ} 39^{\prime} 23^{\prime \prime} \mathrm{W}$ & Colony 12 & [29] \\
\hline CBS $135749^{\text {TC }}$ & Acromyrmex subterraneus subterraneus & Viçosa/MG & $20^{\circ} 44^{\prime} 31.71 " \mathrm{~S} 42^{\circ} 52^{\prime} 43.83^{\prime \prime} \mathrm{W}$ & - & [18] \\
\hline
\end{tabular}

aLESF: Fungal collection of the Laboratory of Ecology and Fungal Systematics (UNESP, Rio Claro, Brazil)

bIsolates LESF 589 and LESF595 were obtained from the same ant colony but in different collecting years, 2013 and 2012 , respectively

Isolates used in the dual-culture assays

'Type species

from stocks by inoculating preserved conidia on PDA medium and incubated for 7 days at $25{ }^{\circ} \mathrm{C}$, in darkness. All isolates examined were obtained as monosporic cultures.

\section{Molecular characterization of Escovopsioides}

Genomic DNA was extracted by the CTAB method from cultures grown on malt agar 2\% (MA2\%) for 5 days, in darkenss [31]. The genes encoding for tef1 (primers: EF6-20F and EF6A-1000R), LSU (primers: CLA-F and CLA-R) as well as ITS (primers: ITS5 and ITS4) were amplified for all isolates. For tefl, $1 \mu \mathrm{L}$ of diluted genomic DNA (1:100) was used as template for amplification using illustra ${ }^{\text {Tu }}$ PureTaq Ready-To-Go PCR Beads (GE Healthcare) under the following conditions: an initial denaturation step at $94{ }^{\circ} \mathrm{C}$ for 2 min, followed by 15 cycles at $94{ }^{\circ} \mathrm{C}$ for $30 \mathrm{~s}$ and initial annealing temperature at $65{ }^{\circ} \mathrm{C}$ decreasing by $1{ }^{\circ} \mathrm{C}$ per touchdown cycle and final extension at $72{ }^{\circ} \mathrm{C}$ for $1 \mathrm{~min}$. A second PCR step was performed: $94{ }^{\circ} \mathrm{C}$ for $30 \mathrm{~s}$, followed by $35 \mathrm{cy}-$ cles at $94{ }^{\circ} \mathrm{C}$ for $30 \mathrm{~s}, 48{ }^{\circ} \mathrm{C}$ for $30 \mathrm{~s}$ and a final extension step at $72{ }^{\circ} \mathrm{C}$ for $1 \mathrm{~min}$. For ITS, $2 \mu \mathrm{L}$ of the diluted genomic DNA (1:100) were used as template for PCR, following the conditions described in Schoch et al. [32]: $94{ }^{\circ} \mathrm{C}$ for $3 \mathrm{~min}$, followed by 35 cycles at $94{ }^{\circ} \mathrm{C}$ per $1 \mathrm{~min}, 55{ }^{\circ} \mathrm{C}$ for $1 \mathrm{~min}$ and a final extension step at $72{ }^{\circ} \mathrm{C}$ for $2 \mathrm{~min}$. For LSU, $2 \mu \mathrm{L}$ of diluted genomic DNA (1:100) were used for PCR, following the conditions described in Augustin et al. [18]: $95{ }^{\circ} \mathrm{C}$ for $2 \mathrm{~min}, 40$ cycles of $30 \mathrm{~s}$ at $95{ }^{\circ} \mathrm{C}, 60 \mathrm{~s}$ at $62{ }^{\circ} \mathrm{C}, 90 \mathrm{~s}$ at $72{ }^{\circ} \mathrm{C}$ and 5 min of extension at $72{ }^{\circ} \mathrm{C}$. PCR products were stained with GelRed ${ }^{\mathrm{mix}}$ (Biotium) and visualized under UV after electrophoresis in 1\% agarose gel.

Amplicons were purified with the Wizard ${ }^{\oplus}$ SV Gel and PCR Clean-up System Kit (Promega) following the manufacturer's protocol. Samples were analyzed in NanoDrop ${ }^{\text {tw }} 2000$ (Thermo Fisher Scientific) and $20 \mathrm{ng}$ of DNA were sequenced using BigDye $^{\mathrm{Tu}}$ Terminator v. 3.1 Cycle Sequencing Kit (Thermo Fisher Scientific) following the manufacturer's instructions. Due to high GC content in the ITS region of Escovopsioides, $5 \%$ of DMSO was added to the sequencing reactions. Forward and reverse sequences were generated in ABI 3500 (Life Technologies) and assembled into contigs in BioEdit v.7.1.3 [33]. Sequences generated in the present study were deposited at NCBI-GenBank (Additional file 1: Table S1).

\section{Phylogenetic analysis}

In addition to the sequences generated in this study, the sequences of the type species (E. nivea) along with of six 
described Escovopsis species and eight fungi belonging to the Hypocreales (Hypomyces, Trichoderma and Lecanicillium) were retrived from the NCBI-GenBank. Thus, the whole dataset used in this study comprised sequences of 37 fungi (Additional file 1: Table S1).

For the phylogenetic analysis, sequences were aligned in MAFFT [34]. Sequences of tef1, ITS and LSU were concatenated in Winclada v.1.00.08. Bayesian inference was used as the reconstruction algorithm. The nucleotide substitution model GTR + G and GTR + I + G was selected for tef1 and ITS/LSU, respectively, using AIC in jModeltest2 [35] with a confidence interval of $95 \%$. Thus, partitioned independent analyses of the dataset were performed in MrBayes [36] each with three heated chains and one cold chain. MCMC sampling in each analysis occurred up to one million generations. Convergence of heated and cold chains occurred when the standard deviation of split frequencies was below 0.01 ; then the first $25 \%$ of generations were discarded as burn-in.

\section{Dual-culture experiments}

We performed in vitro tests to verify the antagonistic potential of Escovopsioides towards the fungus cultivated by leafcutter ants. We selected 13 out of 21 Escovopsioides isolates (Table 3), based on the following criteria: i) any polymorphism found in the tef1 gene; ii) different associated ant species; iii) geographical location (i.e. different cities and collection sites). Two of the selected isolates (LESF 596 and LESF 599) were already evaluated for their interactions with the fungal cultivar in the study of Varanda-Haifig et al. [16]. However, we replicated this assay to compare with additional Escovopsioides isolates.

The fungus Leucoagaricus gongylophorus FF2006 cultivated by the ant species Atta sexdens rubropilosa was used in the dual-cultural experiments. This strain is maintained on agar slants by successive transfers every 24 days at $25{ }^{\circ} \mathrm{C}$. Production of gongylidia by this strain is checked in every transfer cycle. This fungus was grown on PDA medium and incubated at $25{ }^{\circ} \mathrm{C}$ for 14 days, in darkeness. After this period, mycelial fragments ( $8 \mathrm{~mm}$ in diameter) were transfered to new Petri plates $(90 \times 15 \mathrm{~mm})$ also containing PDA at a distance of $1.5 \mathrm{~cm}$ from the border. These plates were incubated at $25{ }^{\circ} \mathrm{C}$ for 14 days, in darkeness. Then, mycelium fragments (8 $\mathrm{mm}$ in diameter) of Escovopsioides, previously incubated on PDA, were inoculated at a distance of $3 \mathrm{~cm}$ apart from the mutualistic fungus. To compare the effects of Escovopsioides on the mycelium growth of the fungal cultivar with the effects caused by other fungi, we used one Escovopsis sp. isolate (LESF 19) from the fungus gardens of Atta sexdens rubropilosa (Botucatu, Brazil). This isolate was obtained by inoculating small pieces of the fungus gardens on PDA supplemented with chloramphenicol. Control plates were inoculated with the same mutualistic fungus, however, no Escovopsioides or Escovopsis were inoculated. All plates were incubated for 14 days at $25{ }^{\circ} \mathrm{C}$, in darkness. Each combination of Escovopsioides, Escovopsis and the mutualistic fungus were carried out in ten plates. Experimental and control plates were scanned at intervals of $0,2,3,5,7,10$ days on a HP Deskjet F2050 scanner. Images were used to measure the area of colony growth $\left(\mathrm{cm}^{2}\right)$ of the mutualistic fungus in ImageJ v. 1.38 [37].

The mycelial growth areas of L. gongylophorus in the dual-culture experiments were analyzed using two-way mixed ANOVA, with fungal isolates (Escovopsioides and Escovopsis) versus the control as the between-subjects variable, and time (days) as the within-subjects variable, thus considering the repetead measurements of time in the treatments. The data were checked for normality and homogeneity of variances, using the Shapiro-Wilk and Levene tests, respectively. Due to the violations of these criteria, data were transformed using the log or square root when necessary. Multiple comparisions with different filamentous fungi were performed using $t$-test with Bonferroni correction.

For comparison between isolates, the mycelial growth area of L. gongylophorus in contact with Escovopsioides isolates was divided by the mean area of its control at day 10 . The data were checked for normality and homogeneity of variances. One-way ANOVA was performed with the area obtained at day 10 between all tested fungi, with comparisons between the different treatments performed using post-hoc Tukey-HSD test. Statistical analyses were performed in R v. 2.12.1 [38].

\section{Bioassays on fungus garden fragments in the absence of workers}

Leucoagaricus gongylophorus is cultivated in attine ant colonies in fungus gardens. To determine whether Escovopsioides can develop on the fungus garden without the possible protective effects of the workers, we performed bioassays using fragments of this substrate free of ants. Fungus garden fragments were obtained from one mature and healthy $A$. sexdens rubropilosa colony maintained at the Center for the Studies of Social Insects (UNESP, Rio Claro). Fungus garden fragments of $2 \mathrm{~cm}^{3}$ deprived of ants and brood were placed in sterile Petri dishes with moistened cotton at the edges (following Elizondo-Wallace et al. [22]). Before carring out the experiments, plates were kept for 1 day at $25{ }^{\circ} \mathrm{C}$ to search for ants that possibly remained in the fragments.

We prepared a $10 \mathrm{~mL}$ suspension of $0.05 \%$ Tween 80 with mycelial mass and conidia of each of the 12 Escovopsioides (isolate LESF 591 was not used in this experiment) and one Escovopsis isolate used in the dual-culture experiments. This suspension was filtered two to three times following the method by Newmeyer [39] to separate the conidia from the 
hyphal fragments present in the suspension. Then, the suspension was diluted to $10^{5}$ to $2.10^{5}$ conidia $\mathrm{mL}^{-1}$ determined in a Neubauer chamber. Aliquots of $100 \mu \mathrm{L}$ of conidia suspensions were inoculated on the surface of the garden fragment using a micropipette. The same amount of sterile 0.05\% Tween 80 solution was added on the garden surface in the negative control. Petri dishes with fungus garden were kept at $25{ }^{\circ} \mathrm{C}$ for up to 10 days, with five dishes used for each treatment and five dishes for each respective control. The possible development of hyphae of the inoculated fungi was observed daily on a stereomicroscope (EZ4, Leica). Escovopsioides conidiation on the fungus gardens was observed by taking mycelium fragments growing on the gardens and mounted in water and observed under the microscope (DM500, Leica).

Growth and conidiation data on the fungus gardens were scored as: no growth (score 0), growth observed only on the stereomicroscope (score 1), macroscopic growth (score 2) and conidiation (score 3 ) over 10 days of monitoring (Additional file 1: Figure S1). We observed conidiation only after fungal macrocospic growth on the fungus gardens. The total sum of the scores of five Petri dishes on each day was obtained and transformed in terms of percentage of the maximum possible total for direct comparisons.

\section{Effects of Escovopsioides on gardens with workers}

Ant workers have an important role in colony defense against pathogens and unwanted microbes in the fungus gardens [40]. Thus, we performed experiments to check the influence of workers in fungus gardens inoculated with conidia of the same fungi used in the bioassays on fungus garden in the absence of ant workers (12 Escovopsioides isolates and 1 Escovopsis isolate).

Bioassays using queen-right ant colonies are challenging due to the large number of colonies this type of experiment would demand. Thus, we performed bioassays with gardens fragments containing workers to assess the effects of the fungal isolates in vivo. Although this experimental set up does not represent what occurs in natural colonies, it showed indicative information about the defensive action of workers against the tested fungi. This bioassay was adapted following the method by Elizondo-Wallace et al. [22]. Plastic containers with a tiny layer of plaster in the bottom were used to avoid desiccation of the fungus gardens. About $20 \mathrm{~cm}^{3}$ of fungus garden from the same colony used in the previous experiment were placed in the plastic containers. The experimental set up comprised a total of 84 containers, so that treatments with conidia of the 13 fungi and the control had six containers each. We selected worker ants with cephalic capsule diameter between 1.0 and $1.6 \mathrm{~mm}$ [41], then 50 of these workers were placed in each container. Workers with less than $1.0 \mathrm{~mm}$ were not counted, and workers with more than $1.6 \mathrm{~mm}$ were excluded. This procedure was adopted to allow homogeneity between the six containers from each treatment as well as between the treatments, because workers in the interval between 1.0 and $1.6 \mathrm{~mm}$ have a significative cleaning activity [41]. The inner surface of the container was coated with Teflon to prevent the ants from escaping.

The containers were incubated at $25{ }^{\circ} \mathrm{C}$ for 3 days to stabilize the fungus gardens. Conidia suspensions were obtained as described above. A total of $1 \mathrm{~mL}$ of conidia suspension was sprayed on the surface of the fungus gardens using a sprayer. Fungus gardens in the negative control were sprayed with only $1 \mathrm{~mL}$ of sterile $0.05 \%$ Tween 80 solution.

The experiments were monitored after 0,5 and 10 days of inoculation to check the health of the fungus gardens. This parameter was based on a scoring system, in which healthy gardens received score 0 , partially degraded gardens received score 1 and completely degraded ("infected") gardens received score 2. The ant removal of fungus gardens pieces and allocation to the refuse dumps was the main sign of garden deterioration we examined (see Additional file 1: Figure S2). The scores obtained from the six containers of each experiment, on the 3 days of observation, were compared using Friedman test.

To verify the presence of the Escovopsioides isolates on the fungus gardens on days 0,5 and 10 after treatment, fragments were removed from gardens and inoculated on MA2\% supplemented with $150 \mu \mathrm{g} \mathrm{mL}^{-1}$ of chloramphenicol. Plates were incubated at $25^{\circ} \mathrm{C}$ for 7 days, in darkness. Five plates with one garden fragment were used for each one of the six containers from each treatment, totaling 30 plates per treatment. Fragments with positive growth were counted and the long-term presence of the inoculated fungi in the fungus gardens was tested using Fisher's Exact test. In this analysis we compared the proportion of frangments infected with fungal conidia (Escovopsioides and Escovopsis) versus the control without any conidia in each day of experiment. We also compared the different treatments with inoculated fungi between each other in each day of experiment.

\section{Additional file}

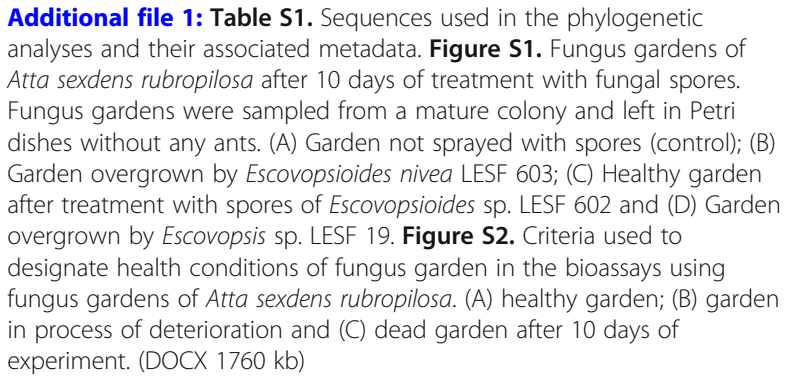

\section{Abbreviations}

AIC: Akaike Information Criterion; CTAB: cetyltrimethyl ammonium bromide; ITS: internal transcribed spacer region; LSU: gene that encodes for the large 
subunit of the ribosomal RNA; MCMC: Markov Chain Monte Carlo; PCR: polymerase chain reaction; PDA: potato-dextrose agar; tef1: gene that encodes for the elongation factor 1-alpha

\section{Acknowledgments}

We are grateful to Sergio Kakazu for sequencing operations, Dr. Odair C. Bueno (CEIS/UNESP, Rio Claro) for providing material for the fungus garden experiments. We are also greatful to Mariana O. Barcoto for providing useful comments on early drafts of this manuscript. We are also grateful to Ted R. Schultz and Jeffrey Sosa-Calvo for providing the colony of Apterostigma megacephala from which the isolate LESF 602 was obtained.

\section{Funding}

This research was funded by "FAPESP - Fundação de Amparo a Pesquisa do Estado de São Paulo" (grant \# 2014/24298-1 to AR). FAPESP funded collections of fungal material in previous studies as well as supported the infrastructure used to carried out this study. "CAPES - Coordenação de Aperfeiçoamento de Pessoal de Nível Superior" provided a scholarship to JFO.

\section{Availability of data and materials}

Sequences from fungi examined in this study are deposited at NCBIGenBank under accessions: MF116012-MF116052 (for ITS and LSU) and MF140947-MF140966 (for tef1). Additional data included in this article are presented in the supplementary material.

\section{Authors' contributions}

Conceived and design the experiments: JFO and AR. Performed the experiments: JFO. Analyzed the data: JFO. Wrote the paper: JFO and AR. All authors read and approved the final manuscript.

\section{Ethics approval and consent to participate}

Not applicable.

\section{Consent for publication}

Not applicable.

\section{Competing interests}

The authors declare that they have no competing interests.

\section{Publisher's Note}

Springer Nature remains neutral with regard to jurisdictional claims in published maps and institutional affiliations.

\section{Received: 30 October 2017 Accepted: 26 September 2018} Published online: 10 October 2018

\section{References}

1. Mayhé-Nunes AJ, Jaffé K. On the biogeography of Attini (Hymenoptera: Formicidae). Ecotropicos. 1998;11:45-54.

2. Weber NA. Gardening ants: the attines. Philadelphia: American Philosophical Society; 1972.

3. Mueller UG, Kardish MR, Ishak HD, Wright AM, Solomon SE, Bruschi SM, Carlson AL, Bacci M Jr. Phylogenetic patterns of ant-fungus associations indicate that farming strategies, not only a superior fungal cultivar, explain the ecological success of leafcutter ants. Mol Ecol. 2018;27:2414-434.

4. Della Lucia TMC, Gandra LC, Guedes RNMC. Managing leaf-cutting ants: peculiarities, trends and challenges. Pest Manag Sci. 2014;70:14-23.

5. Rodrigues A, Cable RN, Mueller UG, MJr B, Pagnocca FC. Antagonistic interactions between garden yeast and microfungal garden pathogens of leaf-cutting ants. Antonie van Leeuwenhoek. 2009;96:331-42.

6. Aylward FO, Burnum KE, Scott JJ, et al. Metagenomic and metaproteomic insights into bacterial communities in leaf-cutter ant fungus gardens. The ISME J. 2012;6:1688-170.

7. Pagnocca FC, Masiulionis VE, Rodrigues A. Specialized fungal parasites and opportunistic fungi in gardens of attine ants. Psyche. 2012;2012:1-9.

8. Barcoto MO, Pedrosa F, Bueno OC, Rodrigues A. Pathogenic nature of Syncephalastrum in Atta sexdens rubropilosa fungus gardens. Pest Manag Sci. 2017;73:999-1009.
9. Reynolds HT, Currie CR. Pathogenicity of Escovopsis weberi: the parasite of the attine ant-microbe symbiosis directly consumes the ant-cultivated fungus. Mycologia. 2004;96:955-9.

10. Santos AV, Dillon VM, Reynolds SE, Samuels RJ. Occurrence of the antibiotic producing bacterium Burkholderia sp. in colonies of the leaf-cutting ant Atta sexdens rubropilosa. FEMS Microbiol Lett. 2004;239:319-23.

11. Currie CR, Scott JA, Summerbell RC, Malloch D. Fungus-growing ants use antibiotic-producing bacteria to control garden parasites. Nature. 1999a:398:701-4.

12. Sen R, Ishak HD, Estrada D, Dowd SE, Hong E, Mueller UG. Generalized antifungal activity and 454-screening of Pseudonocardia and Amycolatopsis bacteria in nests of fungus-growing ants. Proc Natl Acad Sci U S A. 2009; 106:17805-10.

13. Meirelles LA, Mendes TD, Solomon SE, Bueno OC, Pagnocca FC, Rodrigues A. Broad Escovopsis inhibition activity of Pseudonocardia associated with Trachymyrmex ants. Environ Microbiol Rep. 2014;6:389-95.

14. Currie CR, Mueller UG, Malloch D. The agricultural pathology of ant fungus gardens. Proc Natl Acad Sci U S A. 1999:96:7998-8002.

15. Marfetán JA, Romero Al, Folgarait PJ. Pathogenic interaction between Escovopsis weberi and Leucoagaricus sp.: mechanisms involved and virulence levels. Fungal Ecol. 2015;17:52-61.

16. Varanda-Haifig SS, Albarici TR, Nunes PH, Haifig I, Vieira PC, Rodrigues A Nature of the interaction between hypocrealan fungi and the mutualistic fungus of leaf-cutter ants. Antonie van Leeuwenhoek. 2017;110:593-605.

17. Currie CR, Wong B, Stuart AE, Schultz TR, Rehner SA, Mueller UG, Sung GH, Spatafora JW, Straus NA. Ancient tripartite coevolution in the attine antmicrobe symbiosis. Science. 2003;299:386-285.

18. Augustin JO, Groenwald JZ, Nascimento RJ, Mizburti ESG, Barreto RW, Elliot SL, Evans HC. Yet more "weeds" in the gardens: fungal novelties from nests of leaf-cutting ants. PLoS One. 2013;8:e82265.

19. Reis BMS, Silva A, Alvarez MR, Oliveira TB, Rodrigues A. Fungal communities in gardens of the leaf-cutter ant Atta cephalotes in forest and cabruca agrosystems of southern Bahia state (Brazil). Fungal Biol. 2015;119:1170-8.

20. Pereira JS, Costa RR, Nagamoto NS, Forti LC, Pagnocca FC, Rodrigues A. Comparative analysis of fungal communities in colonies of two leaf-cutting ant species with different substratum preferences. Fungal Ecol. 2016;21:68-75.

21. Taerum SJ, Cafaro MJ, Little AEF, Schultz TR, Currie CR. Low host-pathogen specificity in the leaf-cutting ant-microbe symbiosis. Proc R Soc Lond B. 2007:274:1971-8.

22. Elizondo-Wallace DE, Vargas-Ansesio JG, Pinto-Tomá AA. Correlation between virulence and genetic structure of Escovopsis strains from leafcutting ant colonies in Costa Rica. Microbiology. 2014;160:1727-36.

23. Scott JJ, Budsberg KJ, Suen G, Wixon DL, Balser TC, Currie CR. Microbial commuity structure of leaf-cutter ants fungus gardens and refuse dumps. PLoS One. 2010;5:e9922.

24. Rodrigues A, Pagnocca FC, Bacci M Jr, Hebling MJA, Bueno OC, Pfenning LH. Variability of non-mutualist fungi associated with Atta sexdens rubropilosa nests. Folia Microbiol. 2005:50:421-25.

25. Schultz TR, Sosa-Calvo J, Lopes CT, Mueller UG, Bacci M Jr, Vasconcelos HL. The most relictual fungus-farming ant species cultivates the most recently evolved and highly domesticated fungal symbiont species. Am Nat. 2015;185:693-703.

26. Gerardo NM, Caldera EJ. Labile associations between fungus-growing ant cultivars and their garden pathogens. The ISME J. 2007;1:373-84.

27. Meirelles LA, Solomon SE, Bacci M Jr, Wright AM, Mueller UG, Rodrigues A. Shared Escovopsis parasites between leaf-cutting and non-leaf-cutting ants in the higher attine fungus-growing ant symbiosis. R Soc Open Sci. 2015b;2:150257.

28. Gerardo NM, Jacobs SR, Currie CR, Mueller UG. Ancient host-pathogen associations maintained by specificity of chemotaxis and antibiosis. PLoS Biol. 2006;4:e235.

29. Rodrigues A, Pagnocca FC, Bueno OC, Pfenning LH, Bacci M Jr. Assessment of microfungi in fungus gardens free the leaf-cutting ant Atta sexdens rubropilosa (Hymenoptera: Formicidae). Sociobiology. 2005;46:329-34.

30. Rodrigues A, Bacci M Jr, Mueller UG, Ortiz A, Pagnocca FC. Microfungal "weeds" in the leafcutter ant symbiosis. Microb Ecol. 2008;56:604-14.

31. Montoya QV, Meirelles LA, Chaverri P, Rodrigues A. Unraveling Trichoderma species in the attine ant environment: description of three new taxa. Antonie van Leeuwenhoek. 2016;109:633-51.

32. Schoch CL, Seifert KA, Huhndorf S, Robert V, Spouge JL, Levesque CA, Chen W, Fungal Barcoding Consortium. Nuclear ribosomal internal transcribed spacer (ITS) region as a universal DNA barcode marker for Fungi. Proc Natl Acad Sci U S A. 2012;109:6241-6. 
33. Hall TA. BioEdit: a user-friendly biological sequence alignment editor and analysis program for windows 95/98/NT. Nucleic Acids Symp Ser. 1999;41:95-8.

34. Katoh K, Standley DM. MAFFT multiple sequence alignment software version 7: improvements in performance and usability. Mol Biol Evol. 2013;30:772-80

35. Darriba D, Taboada GL, Doallo R, Posada D. jModelTest 2: more models, new heuristics and parallel computing. Nat Methods. 2012;9:772-2.

36. Ronquist F, Teslenko M, van der Mark P, Ayres DL, Darling A, Höhna S, Larget B, Liu L, Suchard MA, Huelsenbeck JP (2012) MrBayes3.2: efficient Bayesian phylogenetic inference and model choice across a large model space. Syst Biol. 61:539-542.

37. Schneider CA, Rasband WS, Eliceiri KW. NIH image to imageJ: 25 years of image analysis. Nat Methods. 2012;9:671-5.

38. R Core Team. R: a language and environment for statistical computing. Vienna, Austria: R Foundation for Statistical Computing; 2016. https://www.R-project.org/

39. Newmeyer, D. (1990) Filtering small quantities of conidial suspensions to remove mycelial fragments. Fungal Genet News 137: 27.

40. Currie CR, Stuart AE. Weeding and grooming of pathogens in agriculture by ants. Proc R Soc Lond B. 2001;268:1033-9.

41. Wilson EO. Caste and division of labor in leaf-cutter ants (Hymenoptera: Formicidae: Atta). I. the overall pattern in Atta sexdens. Behav Ecol Sociobiol. 1980;7:143-56.

Ready to submit your research? Choose BMC and benefit from:

- fast, convenient online submission

- thorough peer review by experienced researchers in your field

- rapid publication on acceptance

- support for research data, including large and complex data types

- gold Open Access which fosters wider collaboration and increased citations

- maximum visibility for your research: over $100 \mathrm{M}$ website views per year

At $\mathrm{BMC}$, research is always in progress.

Learn more biomedcentral.com/submissions 